Article

\title{
Development of an LC-MS Targeted Metabolomics Methodology to Study Proline Metabolism in Mammalian Cell Cultures
}

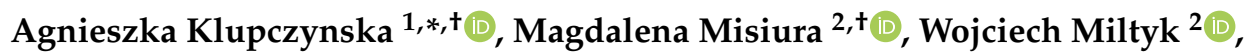

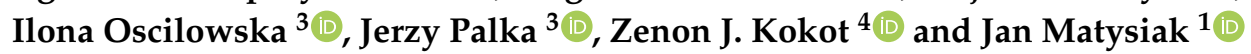 \\ 1 Department of Inorganic and Analytical Chemistry, Poznan University of Medical Sciences, 60-780 Poznan, \\ Poland; jmatysiak@ump.edu.pl \\ 2 Department of Analysis and Bioanalysis of Medicines, Medical University of Bialystok, 15-222 Bialystok, \\ Poland; magdalena.misiura@umb.edu.pl (M.M.); wojciech.miltyk@umb.edu.pl (W.M.) \\ 3 Department of Medicinal Chemistry, Medical University of Bialystok, 15-222 Bialystok, Poland; \\ ilona.zareba@gmail.com (I.O.); pal@umb.edu.pl (J.P.) \\ 4 Faculty of Health Sciences, State University of Applied Sciences in Kalisz, 62-800 Kalisz, Poland; \\ zkokot@ump.edu.pl \\ * Correspondence: aklupczynska@ump.edu.pl; Tel.: +48-61-854-66-16 \\ + These authors contributed equally to this work.
}

Received: 7 September 2020; Accepted: 11 October 2020; Published: 12 October 2020 updates

\begin{abstract}
A growing interest in metabolomics studies of cultured cells requires development not only untargeted methods capable of fingerprinting the complete metabolite profile but also targeted methods enabling the precise and accurate determination of a selected group of metabolites. Proline metabolism affects many crucial processes at the cellular level, including collagen biosynthesis, redox balance, energetic processes as well as intracellular signaling. The study aimed to develop a robust and easy-to-use targeted metabolomics method for the determination of the intracellular level of proline and the other two amino acids closely related to proline metabolism: glutamic acid and arginine. The method employs hydrophilic interaction liquid chromatography followed by high-resolution, accurate-mass mass spectrometry for reliable detection and quantification of the target metabolites in cell lysates. The sample preparation consisted of quenching by the addition of ice-cold methanol and subsequent cell scraping into a quenching solution. The method validation showed acceptable linearity $(r>0.995)$, precision (\%RSD < 15\%), and accuracy (88.5-108.5\%). Pilot research using HaCaT spontaneously immortalized human keratinocytes in a model for wound healing was performed, indicating the usefulness of the method in studies of disturbances in proline metabolism. The developed method addresses the need to determine the intracellular concentration of three key amino acids and can be used routinely in targeted mammalian cell culture metabolomics research.
\end{abstract}

Keywords: metabolomics; cell culture; proline; amino acids; liquid chromatographymass spectrometry

\section{Introduction}

Culture cell metabolomics is a field of metabolomics that has the potential to reflect the phenotype of any cell and enhance our knowledge of cellular biochemistry, functions, and response mechanisms [1]. Cell metabolomics investigations aim to characterize profiles of small molecular weight compounds (typically less than $1500 \mathrm{Da}$ ) and usually focus on capturing changes associated with different signals or perturbations, e.g., gene mutations, pharmacological interventions, exposure to a toxin or stress agents. Moreover, the metabolomics studies employing cultured cells address key biological 
questions, such as metabolic flux in cells and tissues [2] and provide unique insights into metabolic phenomena in cells [3]. Therefore, metabolomics studies of cultured cells were demonstrated to be useful in many areas, including toxicology [4-6], pharmacology [7,8], cancer research [9-12], and biopharmaceutical production [13].

Metabolomics analysis of cell cultures offers many advantages compared with human and animal metabolomics research, where sometimes the researcher does not have strict control over the number of subjects and the type of samples available for a study. The use of established cell lines, animal or human-sourced, does not involve ethical concerns, which may restrict the number of samples or replicates [14]. Furthermore, the benefits of cell culture metabolomics include greater control of external variables, greater reproducibility, and easily interpreted results [14,15]. Variables such as age, sex, BMI, comorbidities, and other sources of inter-individual variability are not issues in culture cell analysis $[15,16]$. To conclude, the use of cultured cells, particularly mammalian cell lines, provides an opportunity to more carefully design intended research and achieve a stronger biological context of the acquired metabolomics data $[1,14]$.

In cultured cell research, there is a need for the application of additional sample processing steps, such as cell metabolism quenching and metabolite extraction, compared to the use of biofluids that usually require only protein precipitation and dilution. The workflow in cell metabolomics encompasses a sequence of many steps, among which selection of cellular model, quenching, sample collection, metabolite extraction, normalization, and selection of analytical platform are the most important $[14,15,17]$. Heedful consideration of the methods employed for each step is required as it minimizes the risk of bias in the acquired data and allows for obtaining reliable results consistent with the purpose of the study.

The majority of the performed cell metabolomics studies were focused on an untargeted strategy (a global metabolite profiling), which aims to detect in a sample as a large number of metabolites as possible [18-21]. However, without knowing compounds of interest a priori, it is hard to develop the most suitable extraction protocols or optimize chromatographic separation. Consequently, there is a risk that some metabolites being critical for the interpretation of results co-elute with each other or are poorly separated. Thus, the metabolomics approach should depend on the study objective. When studying one specific metabolic pathway or a specific metabolite class, a targeted strategy is preferable [17,22]. Targeted metabolomics focuses on monitoring a predefined set of metabolites and permits the optimization of sample preparation protocol and analytical method parameters, offering a high level of precision and accuracy. Moreover, the targeted methods eliminate the need for sophisticated multi-step analysis of the huge amount of data, which is generated in an untargeted strategy to extract useful biological information.

Among amino acids, proline seems to be unique, thus, exploring the role of proline in cellular metabolism is of an emerging interest as this amino acid affects many biological processes such as collagen biosynthesis, proline cycle, intracellular signaling, apoptosis, and autophagy [23,24]. Synthesis of proline involves the enzymatic conversion of pyrroline-5-carboxylic acid (P5C) derived from glutamate or ornithine [25]. In Figure 1A, the structures of proline, arginine, and glutamic acid are displayed, while Figure $1 \mathrm{~B}$ represents a schematic illustration for the proline cycle and its relation to the tricarboxylic acid (TCA) and urea cycle where P5C acts as a mediator between these three cycles. Also, proline may originate from collagen degradation in which proline and its hydroxyl derivative (hydroxyproline) constitute about $25 \%$ of all amino acids [26]. An interesting area of active research involves the importance of proline in cell growth and proliferation. It is known that proline metabolism supports these processes through an enhanced synthesis of glutamine, glutamic acid, and nucleotides [27]. Thus, it is believed that proline-driven metabolic pathways may contribute to accelerated wound healing.

The study aimed to develop a robust and easy-to-use targeted metabolomics method for the determination of the intracellular level of proline and the other two amino acids closely related to proline metabolism: glutamic acid and arginine. Till now, only few methodologies have been developed 
to quantify amino acids in cell extracts [28-32]. Many of them employ a combination of a hydrophilic interaction liquid chromatography (HILIC) and a mass spectrometry (MS) detector, which indicates that it is a useful analytical platform for that purpose [30-32]. The above-cited methods rely on the application of a triple quadrupole mass analyzer operating in a multiple reaction monitoring mode. However, high-resolution mass spectrometers can also be successfully applied for metabolite quantification as they can effectively isolate analyte signal from the background noise and provide sensitive and reproducible measurements [33-35]. The developed method employs HILIC followed by high-resolution, accurate-mass MS for reliable detection and quantification of the target metabolites in cell lysates. The method was validated and then successfully applied to a pilot study of alterations of proline metabolism in spontaneously immortalized human keratinocytes HaCaT cell line. The results from both a series of validation tests and a pilot study on cell lines confirmed that the developed methodology could be used routinely in targeted mammalian cell culture metabolomics research.

A<smiles>N=C(N)NCCCC(N)C(=O)O</smiles>

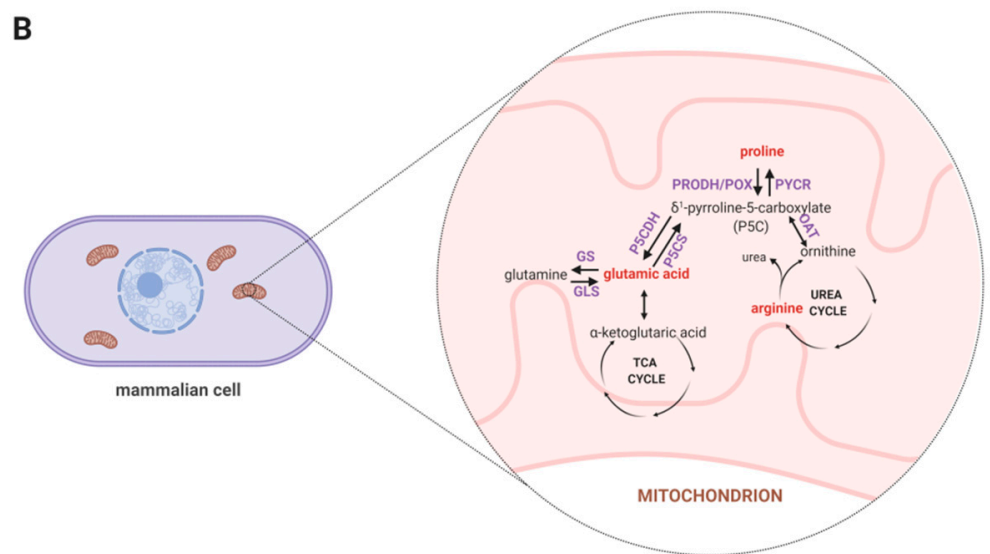

Figure 1. (A) Structures of proline, glutamic acid and arginine. (B) Proline metabolism in mammals. The proline metabolism involves the metabolism of other amino acids, such as ornithine, arginine, glutamic acid, and glutamine, and is related to the urea cycle and TCA cycle. Metabolites covered by the developed methodology are marked in red color. Abbreviations: GDH, glutamate dehydrogenase; GLS, glutaminase; GS, glutamine synthase; OAT, ornithine aminotransferase; PRODH/POX, proline dehydrogenase/oxidase; PYCR, P5C reductase; P5CDH, P5C dehydrogenase; P5CS, P5C synthase; TCA, tricarboxylic acid. Created with BioRender.com.

\section{Results and Discussion}

\subsection{Sample Preparation Method Development}

Metabolomics studies in cultured cells require a strategy to collect samples in a manner to preserve metabolite concentration and then to extract cellular metabolites rapidly. Different quenching methods were described in the literature employing such solutions as ice-cold phosphate buffered-saline (PBS), ice-cold methanol, ice-cold 0.9\% sodium chloride solution, or freezing in liquid nitrogen [14]. The developed method utilizes quenching by the addition of ice-cold methanol with subsequent cell scraping into a quenching solution. This method was shown to be beneficial compared to trypsinization, as it exhibits a higher extraction efficiency of metabolites [14,36-38]. Application of trypsin to detach adherent cells can alter the cellular metabolite levels due to its interaction with membrane proteins 
and can also cause a metabolite leakage through cell membranes [14,38,39]. Therefore, direct scraping of adherent cells was chosen as a method for harvesting (Figure 2).

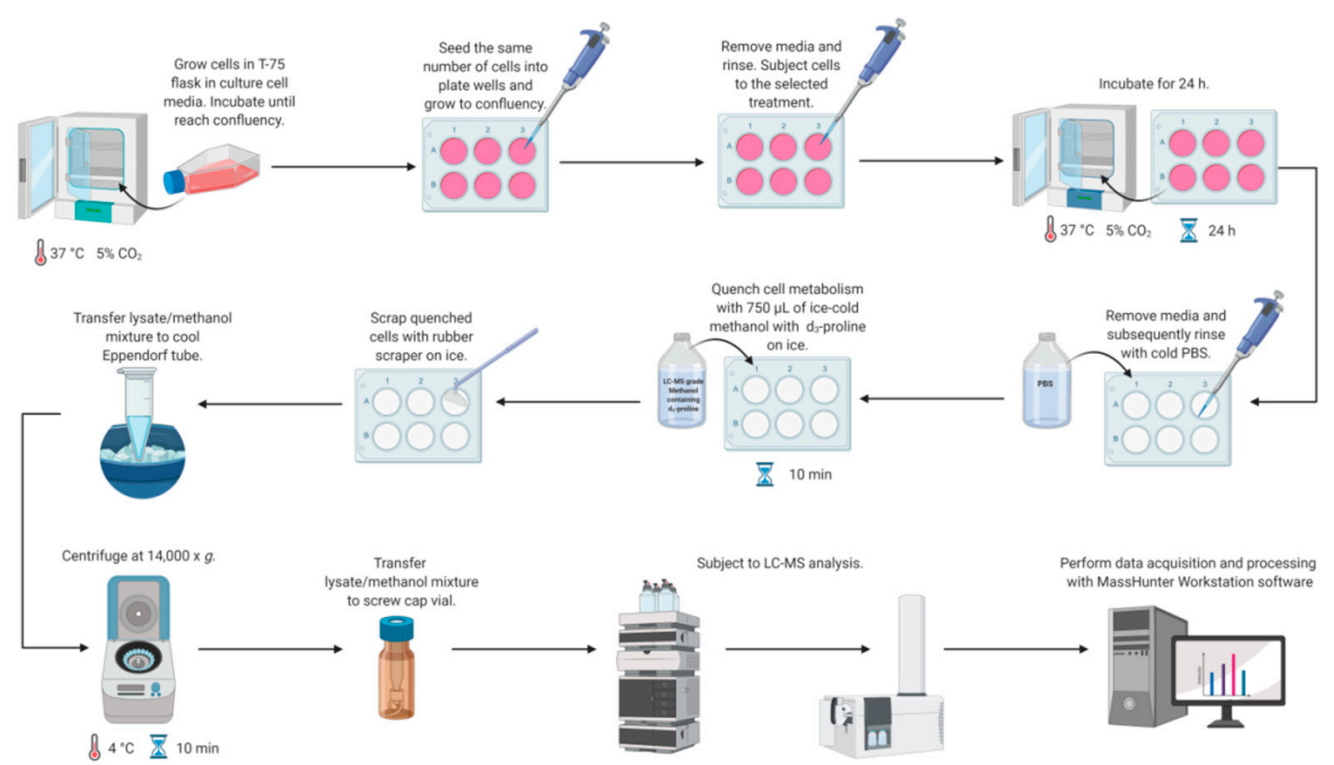

Figure 2. Workflow for LC-MS-based methodology for study proline metabolism in mammalian cell cultures. Created with BioRender.com.

Another critical step in sample preparation of cultured cells is metabolite extraction. In the developed method, extraction with ice-cold methanol was used. The selection of extraction solvent should be study-dependent and thus optimized depending on cell line and metabolites of interest. In untargeted metabolomics investigations, which aim to profile of a broad spectrum of metabolites, a dual-phase extraction using methanol, chloroform (or dichloromethane), and water is recommended. Another strategy is the application of methanol:water mixture (80:20,v/v) [14,40]. The extraction method used in our study was modeled on previous targeted and untargeted metabolomics studies, which utilized $100 \%$ methanol or $80 \%$ methanol [37,41]. According to the study of Bennett et al. [42], methanol extracts amino acids efficiently, and this solvent is preferred for research focused on this metabolite class. We performed a pilot study to compare the extraction efficiency of the target metabolites using two above-mentioned solvents: 100\% methanol and 80\% methanol. The conducted optimization study showed no significant differences in signals of analytes between extraction using pure methanol and methanol:water mixture $(80: 20, v / v)$. Similar extraction efficiency between these two solvents was also demonstrated by Dettmer et al. [37], who tested seven different extraction protocols in metabolomics research of adherently growing mammalian SW480 cells.

\subsection{LC-MS Method Development}

The determination of amino acids using chromatographic techniques is a challenging task. Due to a lack of volatility, amino acids require derivatization before gas chromatography [43,44]. Moreover, amino acids belong to polar metabolites, thus they usually exhibit low retention on a typical C18 column [45]. A traditional method for amino acid determination employs ion-exchange chromatography with post-column ninhydrin derivatization and UV detection [46]. A variety of liquid chromatography-based methods of amino acid determination have been developed, and most of them employ post- or pre-column derivatization [47-49]. Another alternative is the application of HILIC columns. HILIC constitutes a separation mode that employs a polar stationary phase and therefore, this technique is well suited for the analysis of low-molecular-weight polar molecules, such as organic acids or amino acids. HILIC methods require the high organic content of the mobile 
phase, which increases the ionization efficiency in an ion source and thus increases MS sensitivity. Due to the high compatibility with MS and the ability to retain polar metabolites, HILIC has grown in popularity in metabolomics studies, both untargeted and targeted $[45,50,51]$. In the developed method, the HILIC column was applied for the separation of underivatized amino acids, which allowed for the elimination of drawbacks related to chemical modifications of analytes.

In this study, the optimization of chromatographic conditions in terms of mobile phase composition, gradient profile, flow rate, column temperature, and the injection volume was performed. Ammonium formate in two concentrations $-5 \mathrm{mM}$ and $10 \mathrm{mM}$ - was tested as a mobile phase additive. Higher signal intensities and peak areas were obtained using a higher concentration of ammonium formate (Figure S1). Various column temperatures $\left(30^{\circ} \mathrm{C}\right.$ and $45^{\circ} \mathrm{C}$, Figure S2), flow rates $(0.6 \mathrm{~mL} / \mathrm{min}$ and $0.8 \mathrm{~mL} / \mathrm{min})$, and injection volumes $(2 \mu \mathrm{L}$ and $5 \mu \mathrm{L})$ were also assessed. Three different gradient elution modes were tested, and finally, a gradient with increasing the water content up to $70 \%$ and the equilibration step lasting $6 \mathrm{~min}$ was selected. The optimized chromatographic parameters provided adequate separation of peaks of analytes at retention time ranges from 1.5 to $6.5 \mathrm{~min}$ (Figure 3A). The use of a reversed-phase (RP) column-Synergi Fusion RP $(2 \times 100 \mathrm{~mm}, 3 \mu \mathrm{m}$ particle size, Phenomenex)-yielded unsatisfactory retention and separation of analytes as all of them eluted around $1.5 \mathrm{~min}$.

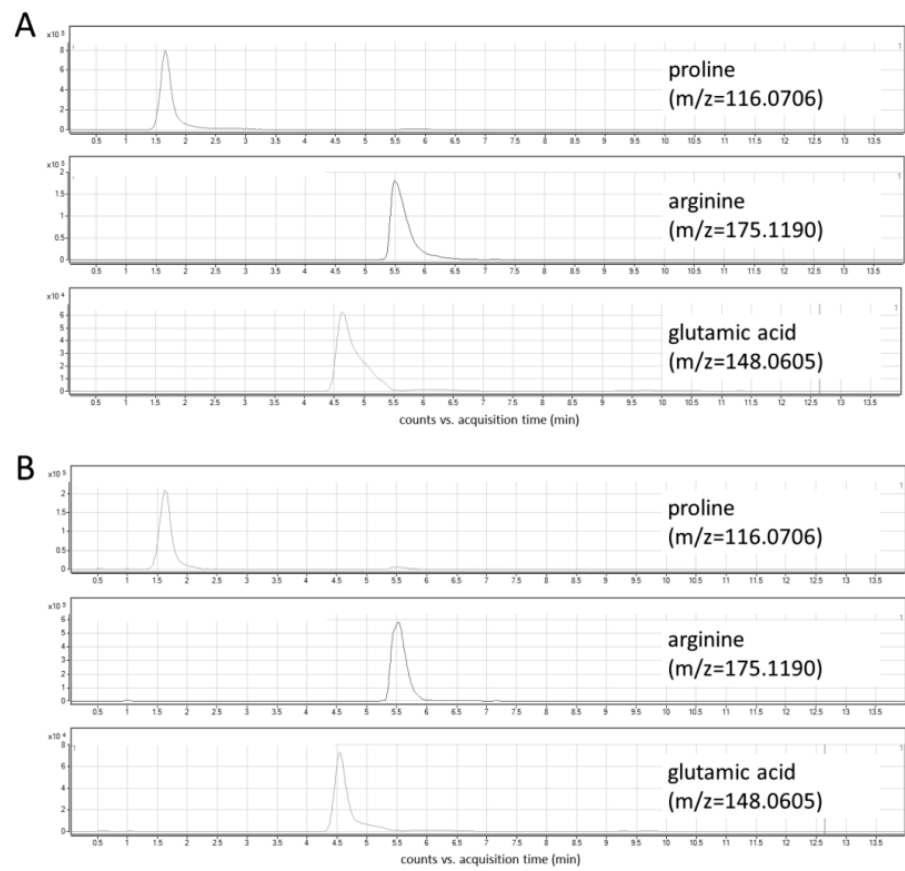

Figure 3. Extracted ion chromatograms of target metabolites: (A) standard solution; (B) cell lysate.

The high-resolution mass spectrometer was used as a detector, which allows for the identification and quantification of target molecules with high sensitivity and specificity. Although triple-quadrupole mass spectrometry-based methods are commonly used for quantitation purposes, high-resolution systems, such as quadrupole-time of flight (Q-TOF) MS or quadrupole (Q)-Orbitrap MS, are also successfully used in metabolite determination [33,34,52]. They provide excellent mass accuracy $(<5 \mathrm{ppm})$ and thus distinguish between analytes and some background interferences, which are not resolved with low-resolution mass spectrometers.

\subsection{Method Validation}

The developed methodology was validated in terms of specificity, carry-over, range, linearity, accuracy, precision, matrix effect, and stability. The successful validation allowed for the application of the method to the pilot study of cultured cells. 
Under the optimized LC-MS conditions, no interferences at the retention times of the analytes were observed in cellular extracts (Figure 3B). In addition, three types of blanks were analyzed to exclude any potential solvent or system contribution: extraction blank (solvent-water treated in the same way as the real sample), solvent blank (methanol used for the metabolite extraction), and mobile phase blank. In all obtained chromatograms, no interfering signals were detected. An injection of a solvent blank following injection of the high concentration standard showed no carry-over at the retention times corresponding to analytes and IS.

All analytes showed acceptable linearity over the range of $1-50 \mu \mathrm{M}$ (proline) or $2.5-50 \mu \mathrm{M}$ (arginine, glutamic acid). The calculated correlation coefficients ( $r$ ) for each amino acid were at least 0.995 and provided evidence of a good fit of the acquired data to the applied linear regression model.

Table 1 shows the intra- and inter-assay precision of the newly developed method calculated for peak areas and concentration values. The \%RSD values obtained for concentrations ranged from $0.18 \%$ to $14.97 \%$ and from $0.66 \%$ to $14.27 \%$ for intra-day and inter-day precision, respectively. Moreover, as illustrated by the data contained in Table 1, the method gave excellent repeatability of the retention times of target metabolites. The percentage recoveries for the target amino acids are given in Table 2. The obtained values were in the range $88.5-108.5 \%$ indicating good accuracy of the method. The accuracy and precision of the method determined using spiking of a surrogate matrix $(1 \mathrm{mg} / \mathrm{mL}$ bovine serum albumin (BSA) in PBS) with standard solutions of analytes were contained in Table S1. All calculated values fell within the acceptance criteria. The \%RSD values obtained for concentrations ranged from $1.78 \%$ to $5.00 \%$ and from $2.75 \%$ to $10.83 \%$ for intra-day and inter-day precision, respectively. The calculated relative error values ranged from $1.46 \%$ to $13.62 \%$ and from $0.08 \%$ to $15.17 \%$ for intra-day and inter-day accuracy, respectively. The determined matrix effects ranged from $82.13 \%$ to $98.79 \%$ (Table 2 ).

Table 1. Relative standard deviation (RSD) values in intra-day and inter-day precision tests of the developed method.

\begin{tabular}{|c|c|c|c|c|c|c|c|}
\hline \multirow[b]{2}{*}{ Analyte } & \multirow[b]{2}{*}{ Sample } & \multicolumn{3}{|c|}{ Intra-Day Precision $(n=5)$} & \multicolumn{3}{|c|}{ Inter-Day Precision $(n=5)$} \\
\hline & & $\begin{array}{c}\mathrm{RT}^{1} \text { (min), } \\
\text { \% RSD }^{2}\end{array}$ & $\begin{array}{l}\text { Peak Area, } \\
\% \text { RSD }^{2}\end{array}$ & $\begin{array}{l}\text { Conc }^{3} \\
\% \text { RSD }^{2}\end{array}$ & $\begin{array}{l}\text { RT }^{1} \text { (min), } \\
\% \text { RSD }^{2}\end{array}$ & $\begin{array}{l}\text { Peak Area, } \\
\%_{\text {RSD }}^{2}\end{array}$ & $\begin{array}{l}\text { Conc }^{3} \\
\% \text { RSD }^{2}\end{array}$ \\
\hline \multirow{4}{*}{ Proline } & QC1 & 0.04 & 2.95 & 0.18 & 0.92 & 10.53 & 0.66 \\
\hline & $\widehat{Q} \mathrm{C} 2$ & 0.74 & 7.25 & 1.29 & 0.69 & 6.21 & 0.84 \\
\hline & QC3 & 1.06 & 7.13 & 1.71 & 0.78 & 6.07 & 1.24 \\
\hline & QC1 & 0.14 & 6.85 & 3.34 & 0.15 & 14.27 & 5.67 \\
\hline \multirow[t]{2}{*}{ Arginine } & QC2 & 0.18 & 1.59 & 12.41 & 0.23 & 4.98 & 8.46 \\
\hline & QC3 & 0.07 & 4.01 & 14.97 & 0.14 & 5.25 & 10.26 \\
\hline \multirow{3}{*}{ Glutamic acid } & QC1 & 0.23 & 6.12 & 4.87 & 0.33 & 7.27 & 5.19 \\
\hline & QC2 & 0.45 & 8.04 & 0.92 & 0.41 & 5.21 & 3.61 \\
\hline & QC3 & 0.31 & 5.65 & 3.40 & 0.33 & 4.17 & 3.68 \\
\hline
\end{tabular}

${ }^{1}$ RT-retention time; ${ }^{2}$ RSD—relative standard deviation; ${ }^{3}$ Conc-concentration value.

Table 2. Mean percentage recoveries of the target metabolites and the determined matrix effect.

\begin{tabular}{ccccc}
\hline \multirow{2}{*}{ Analyte } & \multicolumn{3}{c}{ Recovery, \% } & \multirow{2}{*}{ Matrix Effect $^{\mathbf{1} \%}$} \\
\cline { 2 - 4 } & $\mathbf{Q C 1}(\mathbf{n}=\mathbf{3})$ & $\mathbf{Q C 2}(\mathbf{n}=\mathbf{3})$ & $\mathbf{Q C 3}(\mathbf{n}=\mathbf{3})$ & \\
\hline Proline & 103.76 & 99.96 & 105.84 & 98.79 \\
Arginine & 98.08 & 100.33 & 88.46 & 96.03 \\
Glutamic acid & 103.01 & 99.86 & 108.54 & 82.13 \\
\hline \multicolumn{2}{c}{ 1 determined using a surrogate matrix (1 mg/mL BSA in PBS). }
\end{tabular}

The post-preparative stability of analytes, evaluated relative to fresh samples or fresh standard solutions, are summarized in Table 3 . The data obtained show that the concentration of target metabolites did not change more than $\pm 15 \%$ after $24 \mathrm{~h}$ and $48 \mathrm{~h}$ storage in the autosampler. Therefore, the 
results indicate no substantial decline in response noted after the storage of solutions and samples at ambient temperature.

Table 3. Results of post-preparative stability tests of target metabolites.

\begin{tabular}{cccccc}
\hline \multirow{2}{*}{ Analyte } & \multirow{2}{*}{ Sample } & \multicolumn{2}{c}{ 24 h Storage } & \multicolumn{2}{c}{ 48 h Storage } \\
\cline { 3 - 5 } & & Peak Area, \% & Conc $\mathbf{1}, \mathbf{\%}$ & Peak Area, \% & Conc $\mathbf{1}_{\mathbf{, ~}}$ \\
\hline \multirow{2}{*}{ Proline } & Standard solution & 99.17 & 99.72 & 123.93 & 99.22 \\
& Cell lysate & 104.67 & 99.32 & 112.27 & 99.23 \\
Arginine & Standard solution & 101.25 & 102.97 & 118.05 & 93.24 \\
& Cell lysate & 98.12 & 91.63 & 100.35 & 86.64 \\
Glutamic acid & Standard solution & 94.66 & 95.12 & 118.03 & 93.97 \\
& Cell lysate & 105.47 & 100.03 & 111.28 & 98.27 \\
\hline
\end{tabular}

${ }^{1}$ Conc-concentration value.

The performed validation proved that the developed method can be used as an alternative method for the determination of the intracellular concentration of proline and its' related amino acids. The presented method has lower sensitivity compared with the existing LC-MS/MS methods, which employs a triple quadrupole mass spectrometer [31,32]. While the developed method does not provide the quantification limits of the most advanced triple-quadrupole systems, the sensitivity is more than sufficient for the study of intracellular concentration of proline, arginine, and glutamic acid, which was proved in the performed pilot study using HaCat cell line. Despite that limitation, the present method exhibits numerous advantages, such as a short time of analysis, simple sample preparation, high specificity, accuracy, and precision. The importance of proline in cell regulation $[23,24,53]$ encourages the development of different analytical approaches that offer high throughput and absolute quantitation of metabolites of interest. The present method meets the conditions mentioned above. It constitutes a reliable tool in targeted studies of proline metabolism in cell cultures and can be expanded by adding new metabolites related to the proline metabolic axis, not only belonging to amino acids.

\subsection{Application to Real Samples}

As the proline cycle is reflected in many cellular processes, there is a possibility to apply this method for investigation of metabolic changes of proline and related metabolites under experimental conditions in vitro. The usefulness of the developed methods was proved in the study of proline, glutamic acid, and arginine in the cellular model for wound healing. We performed an analysis of target metabolites in the model for prolidase-promoted wound closure using the HaCaT cell line.

It is known that prolidase is a ligand of an epidermal growth factor receptor (EGFR) [54] promoting pro-growth and pro-proliferation signaling pathways. Since prolidase induces anabolic processes, we were interested in whether and how extracellular prolidase affects proline metabolism. In the prepared $\mathrm{HaCaT}$ cell extracts, we observed that each target amino acid occurred at a measurable level (above LLOQ). The obtained results showed that, when prolidase ( $c=100 \mathrm{nM}$ ) was present in the cell culture medium, intracellular concentrations of proline, glutamic acid, and arginine were greatly increased. The results were normalized to protein concentration and they were calculated per $\mu \mathrm{g}$ protein. The proline concentration determined in prolidase-treated HaCaT cells was $6.31 \pm 0.004 \mu \mathrm{M}$, whereas in control cells (with PBS as a vehicle) equaled $5.29 \pm 0.02 \mu \mathrm{M}$. The level of glutamic acid rose from $26.32 \pm 1.00 \mu \mathrm{M}$ in control to $30.36 \pm 0.10 \mu \mathrm{M}$ in prolidase-treated HaCaT cells. Similarly, the concentration of arginine in control was $5.82 \pm 0.11 \mu \mathrm{M}$ while in treated cells increased to $8.72 \pm 0.09 \mu \mathrm{M}$.

To sum up, the conducted pilot study proved that the developed method is adequate for monitoring the intracellular proline concentration in mammalian cell lines. The developed methodology applied for the study of $\mathrm{HaCaT}$ cells subjected to prolidase treatment under conditions of mechanical damage improved our knowledge about metabolic changes in intracellular cycles involved in EGFR-dependent 
promotion of wound healing. The final interpretation of the results is planned to be performed as it is beyond the study's scope.

\section{Materials and Methods}

\subsection{Reagents}

Standards of analytes (L-proline, L-arginine, L-glutamic acid) and stable isotopically labeled internal standard (L-proline- $\mathrm{d}_{3}, \mathrm{IS}$ ), were bought from Sigma Aldrich (St. Louis, MO, USA). LC-MS grade acetonitrile, formic acid, and ammonium formate were purchased from Sigma Aldrich (St. Louis, MO, USA). Deionized water $\left(18.2 \mathrm{M} \Omega\right.$-cm resistivity at $\left.25^{\circ} \mathrm{C}\right)$ was obtained from the Milli-Q ${ }^{\circledR}$ Advantage A10 water purification system (Merck Millipore, Darmstadt, Germany). The reference mass solution kit and tuning mix for calibrating the Q-TOF-MS were purchased from (Agilent Technologies, Santa Clara, CA, USA).

\subsection{Preparation of Standard Solutions}

Stock solutions $(\mathrm{c}=0.5 \mathrm{M}$ ) of amino acids (analytes and IS) were prepared by dissolving the accurately weighed solids in deionized water. Working solutions of analytes ( $c=5 \mathrm{mM} ; \mathrm{c}=0.5 \mathrm{mM}$; $c=0.05 \mathrm{mM}$ ) were made by mixing all analyte stock solutions together and then diluting the obtained mixture in methanol. Calibration standards were obtained by mixing an appropriate working solution with working IS solution and methanol. For each validation experiment, a new series of standard solutions were prepared.

\subsection{Cell Culture}

HaCaT spontaneously immortalized human keratinocytes were purchased from Cell Line Service $\mathrm{GmbH}$ (Eppelheim, Germany). HaCaT cells were cultured in DMEM cell culture medium (PanBiotech, Aidenbach, Germany) supplemented with $10 \%$ fetal bovine serum (FBS; Gibco, Waltham, MA, USA) and $1 \%$ Penicillin/Streptomycin (Gibco, Waltham, MA, USA). Cells were incubated at $37^{\circ} \mathrm{C}$ in a humidified atmosphere of $5 \% \mathrm{CO}_{2}$. The medium was replaced every 3 days until confluency. For LC-MS-based analysis of the selected amino acids, cells were seeded on 6 -well plates at $2 \times 10^{5}$ cells $/$ well. At $80 \%$ of confluency, HaCaT cells were treated with $100 \mathrm{nM}$ porcine prolidase (Sigma-Aldrich, Saint Louis, MO, USA) for $24 \mathrm{~h}$. Cells subjected to PBS served as a control.

\subsection{Quenching and Extraction}

Simultaneous metabolism quenching and metabolite extraction employing ice-cold methanol was used for targeted metabolomics studies of adherent cell lines. The whole procedure was performed on ice. In the first step, the cell culture medium was aspirated and cells were washed quickly with $0.5 \mathrm{~mL}$ of PBS ( $\mathrm{pH} 7.4$ ) twice to remove any remaining culture medium. Then, $0.75 \mathrm{~mL}$ of $100 \%$ ice-cold methanol $\left(-80^{\circ} \mathrm{C}\right.$, LC-MS grade) containing proline-d3 (IS, $\left.\mathrm{c}=25 \mu \mathrm{M}\right)$ was added to each well on a plate. The plates were incubated on ice for $10 \mathrm{~min}$. Subsequently, cells were harvested using a rubber-tipped cell scraper. Cell lysate/methanol mixture was transferred to an Eppendorf tube, vortexed, and centrifuged $\left(14,000 \times g ; 4{ }^{\circ} \mathrm{C} ; 10 \mathrm{~min}\right)$. The supernatant was transferred to an HPLC vial and subjected to LC-MS analysis. The concentrations of target metabolites were normalized to total protein content determined by BCA Protein Assay (Thermo Fisher Scientific, Waltham, MA, USA). Figure 2 shows all steps of the workflow in the LC-MS-based targeted analysis of proline, glutamic acid, and arginine in mammalian cell culture.

\subsection{Instrumentation and Conditions}

A 1260 Infinity high-performance liquid chromatograph (HPLC, Agilent Technologies, Santa Clara, CA, USA) hyphenated to a 6530 quadrupole-time of flight (Q-TOF) mass spectrometer equipped with a dual electrospray ionization (ESI) source (Agilent Technologies, Santa Clara, CA, USA) source was 
used in the study. Data acquisition and processing were performed with MassHunter Workstation software (Agilent Technologies, Santa Clara, CA, USA).

Chromatographic analyses were conducted using $5 \mu \mathrm{L}$ of sample injected onto a Luna HILIC column $(2 \times 100 \mathrm{~mm}, 3 \mu \mathrm{m}$ particle size, Phenomenex, Torrance, CA, USA). The mobile phase consisted of $10 \mathrm{mM}$ ammonium formate with $0.1 \%$ formic acid in water (solvent $\mathrm{A}$ ) and acetonitrile (solvent $\mathrm{B}$ ). The optimized gradient elution profile was as follows: 0-2 min with $90 \%$ solvent $B, 2-7$ min linear from $90 \%$ to $30 \%$ solvent $B, 7-7.5$ min with $30 \%$ solvent $B$, $7.5-8$ min from $30 \%$ to $90 \%$ solvent $B, 8-14$ with $90 \%$ solvent $\mathrm{B}$. The flow rate was set at $0.6 \mathrm{~mL} / \mathrm{min}$ and the column oven temperature was maintained at $30{ }^{\circ} \mathrm{C}$. Before each injection, the needle was externally washed for $5 \mathrm{~s}$ with $50 \%$ water:50\% isopropanol $(1: 1, v / v)$ using a flush port.

The mass spectrometer was operated in positive ion mode in full-scan MS mode, with nitrogen as the desolvation gas. The ESI source conditions were as follows: drying gas temperature, $325{ }^{\circ} \mathrm{C}$; drying gas flow rate, $12.0 \mathrm{~L} / \mathrm{min}$; capillary voltage, $3000 \mathrm{~V}$; skimmer voltage, $65 \mathrm{~V}$; fragmentor voltage, $140 \mathrm{~V}$ and nebulizer gas pressure at $45 \mathrm{psi}$. Spectra were acquired in an $\mathrm{m} / \mathrm{z}$ scan range of 50-1000 with an acquisition rate of 1 spec sec-1. During all analyses, two reference masses were used: $\mathrm{m} / \mathrm{z} 121.0509$ (protonated purine) and $\mathrm{m} / \mathrm{z} 922.0098$ [protonated hexakis $(1 \mathrm{H}, 1 \mathrm{H}, 3 \mathrm{H}$-tetrafluoropropoxy) phosphazine or HP-921]. The reference mass solution was continuously introduced into the dual ESI source, and the reference mass ions were measured to assure mass correction and mass accuracy performance verification. Samples were injected in random order. Each sample was injected in triplicate into the system.

\subsection{Method Validation}

Method linearity was evaluated by assaying seven non-zero calibration standards in triplicate. Due to the absence of an analyte-free matrix, calibration samples were prepared in methanol. They were prepared on the day of analysis and analyzed with the quality control (QC) samples as a single batch. The calibration curves were constructed using linear regression by plotting the peak area ratio of analyte to IS against the nominal concentration of analytes. The calibration standard with the lowest concentration level was regarded as the lower limit of quantification (LLOQ), having a signal to noise ratio $(\mathrm{S} / \mathrm{N})$ at least 10 and with accuracy within $\pm 20 \%$ of the nominal value, and signal variability represented as percent relative standard deviation (\%RSD) not higher than $20 \%$.

Carry-over was evaluated by injecting solvent blank sample (methanol) after the calibration standard with the highest concentration of analytes. An analyte signal in the blank sample after the analysis of a high concentration standard should not exceed $20 \%$ of the LLOQ, whereas an IS signal should not be greater than $5 \%$.

Precision and recovery of the method were tested using QC samples at different concentration levels. QC samples were prepared by pooling supernatants obtained after metabolite extraction from cell lines. The intra-day precision involved five replicates of $\mathrm{QC}$ samples per each concentration level performed within a single run. To examine inter-day precision, QC samples were analyzed on five consecutive validation days. The precision was satisfactory when the calculated \%RSD of replicates was not higher than $15 \%$. Recovery was determined by spiking QC samples with different amounts of analyte standards and calculated as follows.

$$
\frac{\text { spiked sample result }- \text { unspiked sample result }}{\text { known spike added concentration }} \times 100 \%
$$

As the analytes were endogenous compounds, an additional set of QC samples, prepared by spiking of a surrogate matrix with standard solutions, was analyzed to evaluate method accuracy, precision, and matrix effect. BSA added to PBS is a frequently used surrogate matrix in the determination of endogenous metabolites, which simulates the $\mathrm{pH}$, ionic strength, and protein content of the biological matrix [55-57]. We used $1 \mathrm{mg} / \mathrm{mL}$ BSA solution in PBS, which corresponds to the protein concentration in one well. The spiked surrogate matrix samples were prepared using one-step extraction with $0.75 \mathrm{~mL}$ of 
$100 \%$ ice-cold methanol, as described in Section 3.4. For accuracy determination, relative error (RE, bias) was calculated for each measurement according to the formula presented below.

$$
\frac{\text { calculated value }- \text { nominal value }}{\text { nominal value }} \times 100 \%
$$

Accuracy was found satisfactory when the RE was within $\pm 15 \%$. The precision was satisfactory when the calculated \%RSD of replicates was not higher than $15 \%$. The matrix effect was evaluated by comparison of slopes of calibration curves prepared with and without the surrogate matrix.

Autosampler (post-preparative) stability was evaluated for both standard solutions and cell lysates after $24 \mathrm{~h}$ and $48 \mathrm{~h}$ storage in the autosampler (room temperature). Standard solutions at two concentration levels along with $2 \mathrm{QC}$ samples were tested. The stability was calculated as (area ratio of a sample after storage/area ratio of a freshly prepared sample) $\times 100 \%$.

Supplementary Materials: The following are available online, Figure S1: Extracted ion chromatograms of target metabolites obtained using different mobile phase composition, Figure S2: Extracted ion chromatograms of target metabolites obtained using different column temperatures, Table S1: Intra-day and inter-day validation of the developed methodology performed using quality control $(\mathrm{QC})$ samples at three different concentration levels. The QC samples were prepared by spiking of a surrogate matrix $(1 \mathrm{mg} / \mathrm{mL}$ bovine serum albumin in PBS) with standard solutions of analytes.

Author Contributions: Conceptualization, A.K., M.M., W.M., I.O., J.P. and Z.J.K.; investigation, A.K., M.M. and I.O.; data analysis, A.K., M.M. and J.M.; visualization, A.K. and M.M.; writing-original draft preparation, A.K. and M.M.; writing—review and editing, W.M., I.O., J.P., Z.J.K. and J.M.; supervision, W.M., J.P., Z.J.K. and J.M.; funding acquisition, W.M., J.P. and A.K. All authors have read and agreed to the published version of the manuscript.

Funding: The project received support from the National Science Centre, Poland (grant number: 2017/25/B/NZ7/02650, 2017/25/B/NZ7/02183). A.K. was supported by the Foundation for Polish Science (FNP). The publication was written during doctoral studies under the project № POWR.03.02.00-00-I051/16 co-funded from European Union funds, POWER 2014-2020.

Acknowledgments: The authors would like to thank Szymon Plewa for critical reading of the manuscript.

Conflicts of Interest: The authors declare no conflict of interest. The funders had no role in the design of the study; in the collection, analyses, or interpretation of data; in the writing of the manuscript, or in the decision to publish the results.

\section{References}

1. Zhang, A.; Sun, H.; Xu, H.; Qiu, S.; Wang, X. Cell Metabolomics. Omics 2013, 17, 495-501. [CrossRef] [PubMed]

2. Sims, J.K.; Manteiga, S.; Lee, K. Towards high resolution analysis of metabolic flux in cells and tissues. Curr. Opin. Biotechnol. 2013, 24, 933-939. [CrossRef] [PubMed]

3. Balcke, G.; Kolle, S.; Kamp, H.; Bethan, B.; Looser, R.; Wagner, S.; Landsiedel, R.; Van Ravenzwaay, B. Linking energy metabolism to dysfunctions in mitochondrial respiration-A metabolomics in vitro approach. Toxicol. Lett. 2011, 203, 200-209. [CrossRef] [PubMed]

4. Van Vliet, E.; Morath, S.; Eskes, C.; Linge, J.P.; Rappsilber, J.; Honegger, P.; Hartung, T.; Coecke, S. A novel in vitro metabolomics approach for neurotoxicity testing, proof of principle for methyl mercury chloride and caffeine. Neuro Toxicol. 2008, 29, 1-12. [CrossRef]

5. Kleinstreuer, N.C.; Smith, A.; West, P.; Conard, K.; Fontaine, B.; Weir-Hauptman, A.; Palmer, J.A.; Knudsen, T.; Dix, D.; Donley, E.; et al. Identifying developmental toxicity pathways for a subset of ToxCast chemicals using human embryonic stem cells and metabolomics. Toxicol. Appl. Pharmacol. 2011, 257, 111-121. [CrossRef]

6. Cañaveras, J.C.G.; Castell, J.V.; Donato, M.T.; Lahoz, A. A metabolomics cell-based approach for anticipating and investigating drug-induced liver injury. Sci. Rep. 2016, 6, 27239. [CrossRef]

7. Bai, J.; Wang, M.X.; Chowbay, B.; Ching, C.B.; Chen, W.N. Metabolic profiling of HepG2 cells incubated with $\mathrm{S}(-)$ and $\mathrm{R}(+)$ enantiomers of anti-coagulating drug warfarin. Metabolomics 2011, 7, 353-362. [CrossRef]

8. Wang, M.; Bai, J.; Chen, W.N.; Ching, C.B. Metabolomic Profiling of Cellular Responses to Carvedilol Enantiomers in Vascular Smooth Muscle Cells. PLoS ONE 2010, 5, e15441. [CrossRef] 
9. Chen, Y.; Chen, Z.; Feng, J.; Chen, Y.-B.; Liao, N.-S.; Su, Y.; Zou, C.-Y. Metabolic profiling of normal hepatocyte and hepatocellular carcinoma cells via $1 \mathrm{H}$ nuclear magnetic resonance spectroscopy. Cell Biol. Int. 2018, 42, 425-434. [CrossRef]

10. Semreen, M.H.; Alniss, H.; Cacciatore, S.; El-Awady, R.; Mousa, M.; Almehdi, A.M.; El-Huneidi, W.; Zerbini, L.; Soares, N.C. GC-MS based comparative metabolomic analysis of MCF-7 and MDA-MB-231 cancer cells treated with Tamoxifen and/or Paclitaxel. J. Proteom. 2020, 225, 103875. [CrossRef]

11. Celińska-Janowicz, K.; Zaręba, I.; Lazarek, U.; Teul, J.; Tomczyk, M.; Pałka, J.; Miltyk, W. Constituents of Propolis: Chrysin, Caffeic Acid, p-Coumaric Acid, and Ferulic Acid Induce PRODH/POX-Dependent Apoptosis in Human Tongue Squamous Cell Carcinoma Cell (CAL-27). Front. Pharmacol. 2018, 9, 336. [CrossRef] [PubMed]

12. Seo, S.-H.; Jo, J.K.; Kim, E.-J.; Park, S.-E.; Shin, S.Y.; Park, K.-M.; Son, H.-S. Metabolomics Reveals the Alteration of Metabolic Pathway by Alpha-Melanocyte-Stimulating Hormone in B16F10 Melanoma Cells. Molecules 2020, 25, 3384. [CrossRef]

13. Chong, W.P.K.; Thng, S.H.; Hiu, A.P.; Lee, D.-Y.; Chan, E.C.Y.; Ho, Y.S. LC-MS-based metabolic characterization of high monoclonal antibody-producing Chinese hamster ovary cells. Biotechnol. Bioeng. 2012, 109, 3103-3111. [CrossRef] [PubMed]

14. Hayton, S.; Maker, G.L.; Mullaney, I.; Trengove, R.D. Experimental design and reporting standards for metabolomics studies of mammalian cell lines. Cell. Mol. Life Sci. 2017, 74, 4421-4441. [CrossRef]

15. León, Z.; García-Cañaveras, J.C.; Donato, M.T.; Lahoz, A. Mammalian cell metabolomics: Experimental design and sample preparation. Electrophoresis 2013, 34, 2762-2775. [CrossRef] [PubMed]

16. Cuperlovic-Culf, M.; Barnett, D.A.; Culf, A.S.; Chute, I. Cell culture metabolomics: Applications and future directions. Drug Discov. Today 2010, 15, 610-621. [CrossRef]

17. Kapoore, R.V.; Vaidyanathan, S. Towards quantitative mass spectrometry-based metabolomics in microbial and mammalian systems. Philos. Trans. R. Soc. A Math. Phys. Eng. Sci. 2016, 374, 20150363. [CrossRef]

18. Cambeiro-Pérez, N.; Hidalgo-Cantabrana, C.; Moro-García, M.A.; Alonso-Arias, R.; Simal-Gándara, J.; Sánchez, B.; Martínez-Carballo, E. A Metabolomics Approach Reveals Immunomodulatory Effects of Proteinaceous Molecules Derived from Gut Bacteria over Human Peripheral Blood Mononuclear Cells. Front. Microbiol. 2018, 9, 2701. [CrossRef]

19. Jin, C.; Liu, Y.; Sun, L.; Chen, T.; Zhang, Y.; Zhao, A.; Wang, X.; Cristau, M.; Wang, K.; Jia, W. Metabolic profiling reveals disorder of carbohydrate metabolism in mouse fibroblast cells induced by titanium dioxide nanoparticles. J. Appl. Toxicol. 2012, 33, 1442-1450. [CrossRef]

20. Yu, Z.; Huang, M.; Clowers, B.H. Comparative metabolite profiling of a metastatic and primary melanoma cell line using untargeted metabolomics: A case study. Clin. Mass Spectrom. 2018, 10, 16-24. [CrossRef]

21. Alghamdi, A.A.; Mohammed, M.R.S.; Zamzami, M.A.; Al-Malki, A.L.; Qari, M.H.; Khan, M.I.; Choudhry, H. Untargeted Metabolomics Identifies Key Metabolic Pathways Altered by Thymoquinone in Leukemic Cancer Cells. Nutrients 2020, 12, 1792. [CrossRef] [PubMed]

22. Klupczynska, A.; Derezinski, P.; Kokot, Z.J. Metabolomics in medical sciences-Trends, challenges and perspectives. Acta Pol. Pharm. 2015, 72, 629-641. [PubMed]

23. Zareba, I.; Palka, J. Prolidase-proline dehydrogenase/proline oxidase-collagen biosynthesis axis as a potential interface of apoptosis/autophagy. BioFactors 2016, 42, 341-348. [CrossRef] [PubMed]

24. Misiura, M.; Miltyk, W. Current Understanding of the Emerging Role of Prolidase in Cellular Metabolism. Int. J. Mol. Sci. 2020, 21, 5906. [CrossRef]

25. Albaugh, V.L.; Mukherjee, K.; Barbul, A. Proline Precursors and Collagen Synthesis: Biochemical Challenges of Nutrient Supplementation and Wound Healing. J. Nutr. 2017, 147, 2011-2017. [CrossRef]

26. Surazynski, A.; Donald, S.P.; Cooper, S.K.; Whiteside, M.A.; Salnikow, K.; Liu, Y.; Phang, J.M. Extracellular matrix and HIF-1 signaling: The role of prolidase. Int. J. Cancer 2008, 122, 1435-1440. [CrossRef]

27. Tanner, J.J.; Fendt, S.-M.; Becker, D.F. The Proline Cycle as a Potential Cancer Therapy Target. Biochemistry 2018, 57, 3433-3444. [CrossRef]

28. Hanko, V.P.; Rohrer, J.S. Determination of amino acids in cell culture and fermentation broth media using anion-exchange chromatography with integrated pulsed amperometric detection. Anal. Biochem. 2004, 324, 29-38. [CrossRef] 
29. Ubhi, B.K.; Davenport, P.W.; Welch, M.; Riley, J.; Griffin, J.L.; Connor, S.C. Analysis of chloroformate-derivatised amino acids, dipeptides and polyamines by LC-MS/MS. J. Chromatogr. B Anal. Technol. Biomed. Life Sci. 2013, 934, 79-88. [CrossRef]

30. Li, X.; Wong, C.C.; Tang, Z.; Wu, J.; Li, S.; Qian, Y.; Xu, J.; Yang, Z.; Shen, Y.; Yu, J.; et al. Determination of amino acids in colon cancer cells by using UHPLC-MS/MS and [U-13C5]-glutamine as the isotope tracer. Talanta 2017, 162, 285-292. [CrossRef]

31. Li, J.; Wang, Q.-L.; Liu, Y.; Ke, Y.; Fan, Q.-Q.; Zhou, P.; An, M.-C.; Liu, H.-M. Simultaneous determination of 24 free amino acids in MGC803 cells by hydrophilic interaction liquid chromatography with tandem mass spectrometry. J. Chromatogr. B Anal. Technol. Biomed. Life Sci. 2019, 1132, 121792. [CrossRef] [PubMed]

32. Zhu, B.; Li, L.; Wei, H.; Zhou, W.; Zhou, W.; Li, F.; Lin, P.; Sheng, J.; Wang, Q.; Yan, C.; et al. A simultaneously quantitative profiling method for 40 endogenous amino acids and derivatives in cell lines using hydrophilic interaction liquid chromatography coupled with tandem mass spectrometry. Talanta 2020, 207, 120256. [CrossRef] [PubMed]

33. Gaudiano, M.C.; Valvo, L.; Rodomonte, A.L. A Q-TOF LC/MS method for identification and quantitation of Histamine in the antibiotic Gentamicin at ppm level: Validation and uncertainty evaluation. J. Pharm. Biomed. Anal. 2019, 162, 158-163. [CrossRef] [PubMed]

34. Liu, Z.; Rochfort, S. A fast liquid chromatography-mass spectrometry (LC-MS) method for quantification of major polar metabolites in plants. J. Chromatogr. B Anal. Technol. Biomed. Life Sci. 2013, 912, 8-15. [CrossRef]

35. Williamson, L.N.; Bartlett, M.G. Quantitative liquid chromatography/time-of-flight mass spectrometry. Biomed. Chromatogr. 2007, 21,567-576. [CrossRef]

36. Bi, H.; Krausz, K.W.; Manna, S.K.; Li, F.; Johnson, C.H.; Gonzalez, F.J. Optimization of harvesting, extraction, and analytical protocols for UPLC-ESI-MS-based metabolomic analysis of adherent mammalian cancer cells. Anal. Bioanal. Chem. 2013, 405, 5279-5289. [CrossRef]

37. Dettmer, K.; Nürnberger, N.; Kaspar, H.; Gruber, M.A.; Almstetter, M.F.; Oefner, P.J.; Nurnberger, N.; Kaspar, H.; Gruber, M.A.; Almstetter, M.F.; et al. Metabolite extraction from adherently growing mammalian cells for metabolomics studies. Anal. Bioanal. Chem. 2011, 399, 1127-1139. [CrossRef]

38. Hutschenreuther, A.; Kiontke, A.; Birkenmeier, G.; Birkemeyer, C. Comparison of extraction conditions and normalization approaches for cellular metabolomics of adherent growing cells with GC-MS. Anal. Methods 2012, 4, 1953-1963. [CrossRef]

39. Teng, Q.; Huang, W.; Collette, T.W.; Ekman, D.R.; Tan, C. A direct cell quenching method for cell-culture based metabolomics. Metabolomics 2009, 5, 199-208. [CrossRef]

40. Hounoum, B.M.; Blasco, H.; Nadal-Desbarats, L.; Diémé, B.; Montigny, F.; Andres, C.; Emond, P.; Mavel, S. Analytical methodology for metabolomics study of adherent mammalian cells using NMR, GC-MS and LC-HRMS. Anal. Bioanal. Chem. 2015, 407, 8861-8872. [CrossRef]

41. Yuan, M.; Breitkopf, S.B.; Yang, X.; Asara, J.M. A positive/negative ion-switching, targeted mass spectrometry-based metabolomics platform for bodily fluids, cells, and fresh and fixed tissue. Nat. Protoc. 2012, 7, 872-881. [CrossRef]

42. Bennett, B.D.; Yuan, J.; Kimball, E.H.; Rabinowitz, J.D. Absolute quantitation of intracellular metabolite concentrations by an isotope ratio-based approach. Nat. Protoc. 2008, 3, 1299-1311. [CrossRef] [PubMed]

43. Deng, C.; Li, N.; Zhang, X. Rapid determination of amino acids in neonatal blood samples based on derivatization with isobutyl chloroformate followed by solid-phase microextraction and gas chromatography/mass spectrometry. Rapid Commun. Mass Spectrom. 2004, 18, 2558-2564. [CrossRef]

44. De Paiva, M.J.N.; Menezes, H.C.; Christo, P.P.; Resende, R.R.; Cardeal, Z.D.L. An alternative derivatization method for the analysis of amino acids in cerebrospinal fluid by gas chromatography-mass spectrometry. J. Chromatogr. B Anal. Technol. Biomed. Life Sci. 2013, 931, 97-102. [CrossRef]

45. Tang, D.-Q.; Zou, L.; Yin, X.-X.; Ong, C.N. HILIC-MS for metabolomics: An attractive and complementary approach to RPLC-MS. Mass Spectrom. Rev. 2016, 35, 574-600. [CrossRef] [PubMed]

46. Le Boucher, J.; Charret, C.; Coudray-Lucas, C.; Giboudeau, J.; Cynober, L. Amino acid determination in biological fluids by automated ion-exchange chromatography: Performance of Hitachi L-8500A. Clin. Chem. 1997, 43, 1421-1428. [CrossRef]

47. Shi, T.; Tang, T.; Qian, K.; Wang, F.; Li, J.; Cao, Y. High-performance liquid chromatographic method for determination of amino acids by precolumn derivatization with 4-chloro-3,5-dinitrobenzotrifluoride. Anal. Chim. Acta 2009, 654, 154-161. [CrossRef] 
48. Li, W.; Hou, M.; Cao, Y.; Song, H.; Shi, T.; Gao, X.; Wang, D. Determination of 20 Free Amino Acids in Asparagus Tin by High-Performance Liquid Chromatographic Method after Pre-Column Derivatization. Food Anal. Methods 2012, 5, 62-68. [CrossRef]

49. Shang, S.F.; Wang, H. Sensitive determination of amino acids in kelp by reversed phase high performance liquid chromatography with precolumn derivatization using phenylisothiocyanate. Chromatographia 1996, 43, 309-312. [CrossRef]

50. Onorato, J.M.; Langish, R.; Bellamine, A.; Shipkova, P. Applications of HILIC for targeted and non-targeted LC/MS analyses in drug discovery. J. Sep. Sci. 2010, 33, 923-929. [CrossRef] [PubMed]

51. Guo, C.; Xue, Y.; Seddik, H.E.; Yin, Y.; Hu, F.; Mao, S. A quantitative HILIC-MS/MS assay of the metabolic response of Huh-7 cells exposed to 2,3,7,8-tetrachlorodibenzo- $p$-dioxin. Metabolites 2019, 9, 118. [CrossRef]

52. Ghosson, H.; Schwarzenberg, A.; Jamois, F.; Yvin, J.-C. Simultaneous untargeted and targeted metabolomics profiling of underivatized primary metabolites in sulfur-deficient barley by ultra-high performance liquid chromatography-quadrupole/time-of-flight mass spectrometry. Plant Methods 2018, 14, 62. [CrossRef] [PubMed]

53. Phang, J.M. Proline Metabolism in Cell Regulation and Cancer Biology: Recent Advances and Hypotheses. Antioxidants Redox Signal. 2019, 30, 635-649. [CrossRef] [PubMed]

54. Yang, L.; Li, Y.; Ding, Y.; Choi, K.-S.; Kazim, A.L.; Zhang, Y. Prolidase Directly Binds and Activates Epidermal Growth Factor Receptor and Stimulates Downstream Signaling. J. Biol. Chem. 2012, 288, 2365-2375. [CrossRef]

55. Golja, M.V.; Trontelj, J.; Geršak, K.; Mlinarič-Raščan, I.; Šmid, A. Simultaneous quantification of intracellular concentrations of clinically important metabolites of folate-homocysteine cycle by LC-MS/MS. Anal. Biochem. 2020, 605, 113830. [CrossRef] [PubMed]

56. Zhang, S.; Jian, W.; Sullivan, S.; Sankaran, B.; Edom, R.W.; Weng, N.; Sharkey, D. Development and validation of an LC-MS/MS based method for quantification of 25 hydroxyvitamin D2 and 25 hydroxyvitamin D3 in human serum and plasma. J. Chromatogr. B Anal. Technol. Biomed. Life Sci. 2014, 961, 62-70. [CrossRef]

57. Soh, S.F.; Yin, X.; Sun, J.; Li, J.; Yong, E.-L.; Wei, Q.; Gong, Y. Simultaneous determination of multiple androgens in mice organs with liquid chromatography tandem mass spectrometry. J. Pharm. Biomed. Anal. 2015, 115, 457-466. [CrossRef]

Sample Availability: Samples of the compounds are not available from the authors.

(C) 2020 by the authors. Licensee MDPI, Basel, Switzerland. This article is an open access article distributed under the terms and conditions of the Creative Commons Attribution (CC BY) license (http://creativecommons.org/licenses/by/4.0/). 